\title{
Poesía latinoamericana, un esbozo.
}

\author{
Fecha de recepción: 25 de octubre de 2011 - Aceptación: 11 de noviembre de 2011
}

\section{Juan Gustavo Cobo Borda}

\section{Resumen}

En el 2012, el Fondo de Cultura Económica publicará una amplia antología de la poesía latinoamericana del siglo XX con selección y prólogo de Juan Gustavo Cobo Borda. Adelantamos dos capítulos de su estudio introductorio.

\section{Abstract}

In 2012, the Economic Culture Fund will publish a comprehensive anthology of the Latin American poetry of the twentieth century with the selection and preface of Juan Gustavo Cobo Borda. Here, we present two chapters of his introductory study.

\section{Palabras clave}

Poesía, Latinoamérica, literatura

\section{Keywords}

Poetry, Latin America, Literature
"El movimiento de libertad que me tocó iniciar en América se propagó hasta España, y tanto aquí como allá el triunfo está logrado": así escribía Rubén Darío (1867 1916) dando inicio a la fiesta de libertad de nuestro idioma. Allí se daba el entusiasmo pero también la pesadumbre. La música y la cavilación insomne. Lo fatal y la canción de otoño en primavera. En 1905 dirá:

"La torre de marfil tentó mi anhelo; quise encerrarme dentro de mí mismo, y tuve hambre de espacio y sed de cielo desde las sombras de mi propio abismo".

Estos Cantos de vida y esperanza son capaces de conciliar, en "celeste unidad", Eros y
Thanatos, Caupolicán y El Quijote y, claro está, la tarde tropical. Porque el era "un universo de universos" y su alma, "una fuente de canciones", canciones que aún nos emocionan y estremecen, y que aún vivifican el idioma y los poetas que trajinan con sus sílabas. "Yo persigo una forma que no encuentra mi estilo" escribió en 1900, para abrir el siglo, y continuó: "Y no hallo sino la palabra que huye". La forma que define y la forma que congela. Que encierra en sí el enigma y lo abre al ojo de la lectura. Que apresa y se evade.

"El sollozo continuo del chorro de la fuente y el cuello del gran cisne blanco que me interroga". 
Con la utilería de los jardines de Francia, logró ser un auténtico americano, para hablarnos de Palenque, para increpar la voracidad norteamericana, para llorar de nuevo ante los volcanes de su Nicaragua y el vaho campesino de sus vacas. Había recorrido el mundo y había anunciado la señal de los nuevos tiempos.

En 1909, Rubén Darío, corresponsal en Europa del diario La Nación de Buenos Aires narraba en una crónica la publicación en Le Figaro de Paris del primer manifiesto futurista firmado por Marinetti. El cisne sería sustituido por el automóvil y la velocidad contagiaba, con impaciencia de telegrama, las fotografías y postales de un mundo vasto desde la ventanilla del avión o la sorpresa mecánica de la torre Eiffel.

En 1916, en la editorial argentina Orion,

\section{Reseña de autor \\ Juan Gustavo Cobo Borda \\ www.coboborda.org \\ coborda@gmail.com \\ Colaborador Revista Poliantea}

Poeta y ensayista bogotano. Fue director durante una década (1973-1984) de la revista Eco, de la librería Buchholz, y Gaceta, del Instituto Colombiano de Cultura. Ha ocupado cargos diplomáticos en Buenos Aires y Madrid y fue embajador en Grecia. Miembro número de la Academia Colombiana de la Lengua desde 1993, y correspondiente, de la Academia Española. Ha sido jurado tres veces del Premio Juan Rulfo, (Guadalajara, México); del Rómulo Gallegos, (Caracas); del Reina Sofía de poesía iberoamericana (Madrid) y del Neustad, Universidad de Oklahoma, Estados Unidos. Ha colaborado con otras publicaciones, como Plural, de México, $A B C$, de España, y El Nacional de Venezuela.

Entre sus poemarios figuran Consejos para sobrevivir (1974); Todos los poetas son santos (1987); Dibujos hechos al azar de lugares que cruzaron mis ojos (1991) y La musa inclemente (2001), entre otros. Algunas de sus publicaciones son Lengua Erótica: antología poética para hacer el amor(Villegas Editores, 2004), Lector impenitente, El olvidado arte de leer, Enclave de palabras número tres Acosado animal (Politécnico Grancolombiano, 2010), Vargas Llosa: La pasión de narrar (Alfaguara, 2010), sus más recientes publicaciones. un poeta chileno nacido en 1893 , Vicente Huidobro, había publicado su libro El espejo del agua. Allí un poema, titulado "Arte poética", abre los ojos al nuevo estremecimiento, trayéndonos recuerdos del porvenir. "Que el verso sea como una llave / Que abra mil puertas".

"Inventa mundos nuevos y cuida tu palabra / el adjetivo, cuando no da vida, mata".

Qué pertinente todo ello, aún; y qué acertada la definición siguiente: "Estamos en el ciclo de los nervios". Y luego ésta constancia, tan fecunda para el trabajo subsiguiente:

"El vigor verdadero

Reside en la cabeza".

Por ello su consigna final, aún tiene vigencia:

"Por qué cantáis la rosa, ¡oh Poetas!

Hacedla florecer en el poema”.

En diciembre de 1921 Jorge Luis Borges, de regreso de España, publica los dos primeros y únicos números de la revista mural Prisma. Allí se pedía "sintetizar la poesía en su elemento primordial: la metáfora”. A Prisma seguiría Proa y la eficacia clandestina de las revistas de poesía, por todo el continente. También la cosecha de libros, muy capaces de traspasar fronteras y cambiar rutinas, en ediciones minoritarias. Tal el caso de Prismas de Eduardo González Lanuza; Veinte poemas para ser leídos en el tranvía y Calcomanías de Oliverio Girondo, Bazar y Kindergarten de Francisco Luis Bernárdez y La calle de la tarde, de Norah Lange, con prólogo de Borges, para referirnos solo a la Argentina. Pero el movimiento era continental. No se podía llamar tan solo 
ultraísmo o creacionismo : eran todos los ismos. El fecundo desorden de la palabra de nuevo sacudida y renovada. Con agitación de cine mudo y desgarrón emotivo de inmigrante que hace del tango - "Cambalache. Siglo XX” - su nueva voz. Así lo escucharemos en Raul Gonzalez Tuñon, y en tantos otros.

No es raro, entonces, que los 60 números de la revista Voces, aparecida en Barranquilla, Colombia, entre 1917 y 1920, acogiera en sus páginas poemas de Vicente Huidobro y José Juan Tablada. Apollinaire, Reverdy y Max Jacob. José María Eguren, Carlos Pellicer y muchos de León de Greiff. El peruano Alberto Hidalgo y perfiles del mexicano Amado Nervo. Había integración. Debate y vida literaria. Comunicación. Se revisaba el pasado, en la figura de José Asunción Silva, y se anunciaban los nuevos horizontes. La poesía viva y libre ya circulaba por todo el continente americano.

\section{Del campo a la ciudad}

De "la paz agraria y transparente" habla Jorge Carrera Andrade y esa circunstancia se vuelve a modular tanto en Leopoldo Marechal como en Carlos Mastronardi: lo infinito de la pampa y la dulzura que anida entre árboles que se miran en el agua. Pero ese lenguaje embelesado contrasta con la voz que exalta la embriaguez y el límite, como en Luis Cardoza y Aragón o que comprueba como en José Gorostiza, "que su hermoso lenguaje se le angosta"... "exhausto de sentido", como en Muerte sin fin. Entre tales dilemas avanza esta poesía, a partir de los nacidos en 1900, ya conscientes de ese siglo que hablará, ante todo, inglés, como en poemas de Nicolás Guillén pero que vuelve a oponer la música popular del español y su modulación colectiva en todos los poetas de todos los países que se comunican en tal lengua. Tal la alegría de este diálogo múltiple, en prosa y en verso, en su sensualidad e inteligencia, en recreación de la herencia (Cardoza, como Lezama Lima, devora a Góngora) o termina por asumir lo fecundo del silencio. Solo que lo metafísico no cancela lo cotidiano. El ser y la nada, el otro y lo luminoso trascendente puede darse con "monedas, estilógrafos, cucharas" o una misma montaña contemplada por Martín Adán y Pablo Neruda quienes nos dan dos Macchu-Pichus totalmente distintos. Dos almas, dos espíritus, que lo recubren con sus visiones propias e intransferibles.

Del mismo modo, entre "la hecatombe del amor" y al responder "por cada poro al poderío de tu nombre de mi cuerpo al poderío de tu nombre o poesía" la figura de César Moro se sitúa de lleno en una dramática encrucijada. La del deseo que busca configurar, en un rapto carnal, la belleza de la bestia en su acecho feroz, en su esplendor sin ocaso.

"El grito de la sangre" como responderá Xavier Villaurrutia con "el vaho del deseo " y "la fragancia sin nombre de la piel". Pero todo ello tendrá su reverso: lo fantasmal del sueño y la conversión en una helada estatua de mármol al amanecer. En las plazas desiertas de Giorgio de Chiricó, el amante solo encuentra el grito de la pérdida, el cuchillo del adiós. El vacío, la soledad y el aburrimiento. Ya no el campo, ya no la paz de provincia con su música de retreta y organillo que dibujaron Eugenio Florit y Eliseo Diego en la provincia cubana, sino 
la ciudad desangelada por donde se evaden los fantasmas o se amontonan los parias, como lo vio muy bien Jaime García Terrés. Padecemos ahora un habla "empalagosa y vulgar" como lo dijo Ramón Palomares al venir también del campo a la ciudad y descubrir al final de ese despojo, como lo señaló Rafael Cadenas, "solo quedaban los objetos, los firmes objetos".

Si Villaurrutia busca crear la rosa "inmaterial", la que no ocupa lugar en el espacio, es porque toda su poesía apunta a ese hueco que ha dejado en el lecho el fantasma que abrazó y se ha vuelto humo. Sombra y negrura. Por ello todos sus poemas pueden llamarse "nocturno". Pero también está allí el juego del lenguaje al otorgar a sus pala- bras, en sus afinidades de sonido, un carácter exploratorio de búsqueda, de " huella de vocales perdidas", de rastros de ceniza adhiriéndose a inalcanzables siluetas inmateriales. Pero sí hay una certidumbre: el frio de la soledad, los rasgos que el espejo no refleja, el hielo en que concluye ese ardiente combate. Al final, en la alcoba, solo reina la muerte. Escenario de soledad y naufragios. De ciudad que recorre sabiéndola sumergida en la perplejidad del Dios mismo que la creó y que ahora la abandona, estéril y violenta, donde todos los pecados capitales no se sacian nunca, en bocas voraces que solo consiguen una postrer revelación : amar es al fin una indolencia. 